\title{
Disseminating Cervical Cancer Knowledge: Impact of a Public Seminar
}

\author{
Dr. Saadat Parhizkar \\ Social Determinants of Health Research Centre, Yasuj University of Medical Sciences \\ (YUMS), Yasuj, Iran \\ Tel: 98-741-2229224 E-mail: parhizkarsa@gmail.com
}

Dr. Latiffah Abdul Latiff (Corresponding author)

Department of Community Health, Faculty of Medicine and Health Sciences

Universiti Putra Malaysia (UPM)

Tel: 603-8947-2537Email: latiffahl@gmail.com

Dr. Mojgan Afshari

Department of Educational Management, Planning and Policy, Faculty of Education, University of Malaya (UM), Malaysia

Tel: 603-8947-2537Email: latiffahl@gmail.com

Accepted: Feb 24, 2012 Published: March 17, 2013

Doi:10.5296/ijld.v3i1.3387ＵRL: http://dx.doi.org/10.5296/ijld.v3i1.3387

\begin{abstract}
Cervical cancer is the second most common cancer after breast cancer among women in Malaysia. Cervical cancer screening using Pap smear provides an appropriate way for early detection and prevention of cervical cancer if appropriately implemented. Knowledge and attitudes toward disease and illness have been shown to influence cervical cancer screening in populations. This study was carried out to evaluate the immediate effects of an educational intervention through a scientific seminar on short-term knowledge acquisition. A quasi-experimental pre-test /post-test design was used to assess the efficacy of the public seminar on cervical cancer awareness among Malaysian women. A public seminar was organized by Faculty of Medicine and Health Science University Putra Malaysia. This public seminar focused on how Cervical Cancer Screening can be more accepted by most women in Malaysia and many other Asian and Middle East countries. Data were gathered via a self-administered questionnaire as pre-test. Immediately after delivering speeches by keynote speakers; post-test was carried out. The finding revealed that correct responses increased from $39 \%$ (pre seminar) to $71 \%$ (post seminar) and there was a significant difference in means scores of knowledge and attitude in pre-test and post-test $(\mathrm{P}<0.001)$. An educational intervention had a positive effect on short-term knowledge and awareness of cervical cancer in Malaysian
\end{abstract}


women. Additional research is necessary to assess long-term retention of information and what effect, if any, increased knowledge has on health behaviour.

Keywords: Awareness, Cervical cancer, Education, Public lecture implication

\section{Introduction}

According to the World Health Organization, cervical cancer (CC) is the fifth leading cause of cancer-related death amongst women worldwide. As a disease attributed primarily to the sexually transmitted human papillomavirus (HPV), the pre-cancerous cells of CC can be detected by cervical cytology screening tests known as "Papanicolaou Smear", identified as "Pap Smear Tests" (PST) (Kotaska and Matisic, 2003). By conducting regular PST for early detection of cervical abnormalities, there exists a $30 \%$ reduction in the risk of developing CC if tests are carried out every 10 years, $80 \%$ every 5 years and 90\% every 3 years (Kuie, 1996).

In Malaysia, like other middle and high income countries, CC accounts for a relatively important share of cancer related mortality and morbidity. The National Cancer Registry reported that $\mathrm{CC}$ is the second most common cancer amongst females, constituting $12.9 \%$ of all female cancer patients with peak incidence between 60 and 69 years of age. According to Shamsuddin and Zailiza (2001), only $27.7 \%$ of women staff members of a Malaysian university reported undergoing a PST within the last three years and $16.0 \%$ had one more than three years ago. Others such as Chee et al. (2003) noted prevalence rates of $18.4 \%$ for examinations amongst women workers in selected electronics factories in Malaysia. In other words, even though CC may be one of the most preventable types of cancer today, dissemination of information about this health risk as well as its preventive measures may be still lacking and may not have been accurately targeted at the population of germane interest.

PST was introduced to Malaysia during the late 1960s and early 1970s. However, despite an improvement in the prevalence of testing among women aged 20 years and above in the Third National Health and Morbidity Survey (NHMS III) in 2006 (45.7\%) compared to the NHMS II in 1996 (26.0\%) (Institute for Public Health, 2008), there has been no known accompanying reduction in the prevalence of CC to date. In fact, Wong et al. (2009) noted that there is still a lack of knowledge and awareness of $\mathrm{CC}$ and screening among Malaysian women. Educational and attitudinal barriers have been identified as major reasons for low screening prevalence in developing countries (Leyva, Byrd, \& Tarwater, 2006; Markovic, Kesic, Topic, \& Matejic, 2005; Reyes-Ortiz et al., 2007). This study was carried out to evaluate the immediate effects of an educational intervention through a scientific seminar on short-term knowledge acquisition.

\section{Methods}

The purpose of current study was to determine the effect of health education on the knowledge and attitude regarding cervical cancer and its screening method among the women who participated in a scientific seminar. The study was conducted in Faculty of Medicine and Health Sciences, University Putra Malaysia, located $22 \mathrm{~km}$ South of Kuala Lumpur, the capital city of the country.

\subsection{Study Design, Study Participants and Sampling}

A quasi-experimental design using pre- and post-intervention measurement was used to investigate the effect of an educational intervention through a scientific seminar on the participants' knowledge and attitude. The interventional education consisted of a whole day ( 8 hours) seminar covering 8 sessions including related contents of cervical cancer lectured by 
five lecturers as well as discussion panel including questions and answers concerning cervical cancer which allow the participants to express their ambiguity in understanding. A scientific seminar open to public was organized by Faculty of Medicine and Health Science in collaboration with Laboratory for Cancer Research UPM-MAKNA, Institute of Bioscience University Putra Malaysia. This public seminar focused on how Cervical Cancer Screening can be more accepted by most women in Malaysia and many other Asian and Middle East countries. Lectures were delivered by keynote speaker; Professor Sadamu Noda from Japan one of the scientists pioneered in the invention of Self Administered Cervical Cancer Device (KATO device) and other authorities in Ministry of Health and different universities in Malaysia. A total of 135 participants enrolled in the study using convenience sampling method. Among them just 107 participants responded to post-test, so the analysis has done on 107 participants. The study flowchart illustrated in figure 1.

\subsection{Research Instruments}

Pre and post interventional data was gathered using a structured questionnaire which was developed based on previous studies on cervical cancer. It consisted of three parts: The first part of the questionnaire was demographic data. The second part of the questionnaire consisted of questions regarding knowledge on cervical cancer, its risk factors and screening methods and the third part comprised of questions regarding attitude toward cervical cancer and screening 5 point Likert Scale questions. Content validity was ascertained by an expert panel comprising professionals who were professors and lecturer of Faculty of Medicine and Health sciences, health practitioners and family physicians. Pilot study was carried out on 30 women not included in the study. It was performed as an initial step for the study to check the questionnaire. Some modifications in some questions were done after the pilot study. Its reliability also was determined by alpha-Krunbach $(\mathrm{r}=0.78)$ considering the fact that a reliability coefficient (alpha) of .70 or higher is considered acceptable reliability (Wells and Wollack, 2003).

\subsection{Study Procedure}

After receiving a verbal consent from respondents, pre - interventional assessment was done using the structured questionnaire measuring the respondent's knowledge and attitude regarding cervical cancer written in both English and Malay language. The questionnaire took about 15 minutes to be completed. The scientific lectures were delivered by the speakers which lasted approximately 1 hour for each speech. Visual aids were used to further guide of the respondents during the sessions. Questions were encouraged and a panel discussion (1.5 hours) after all lectures followed. Topics discussed during the lectures were the overview of Cervical Cancer in Malaysia, cervical cancer risk factors, Present status of cervical Cancer screening, its challenges and guideline management of abnormal cervix, opportunities and barriers in cervical cancer screening, the role of HPV-Vaccination in preventing cervical cancer and the self administered Pap test (The Kato-Method) as well as its usefulness and implications for cervical cancer screening particularly in which societies that embracement could be a major barrier.

\subsection{Statistical Analysis}

Data were entered and analyzed using the Statistical Program for Social Sciences (SPSS) version 16. Each knowledge question was scored 1 for a correct response and 0 for either an incorrect response or don't know. A summary score was calculated for each subjects' 
responses at the pre and post-intervention data. Each attitude question was scored from 0 to 4 . The criterion for statistical significance was set at 0.05 .

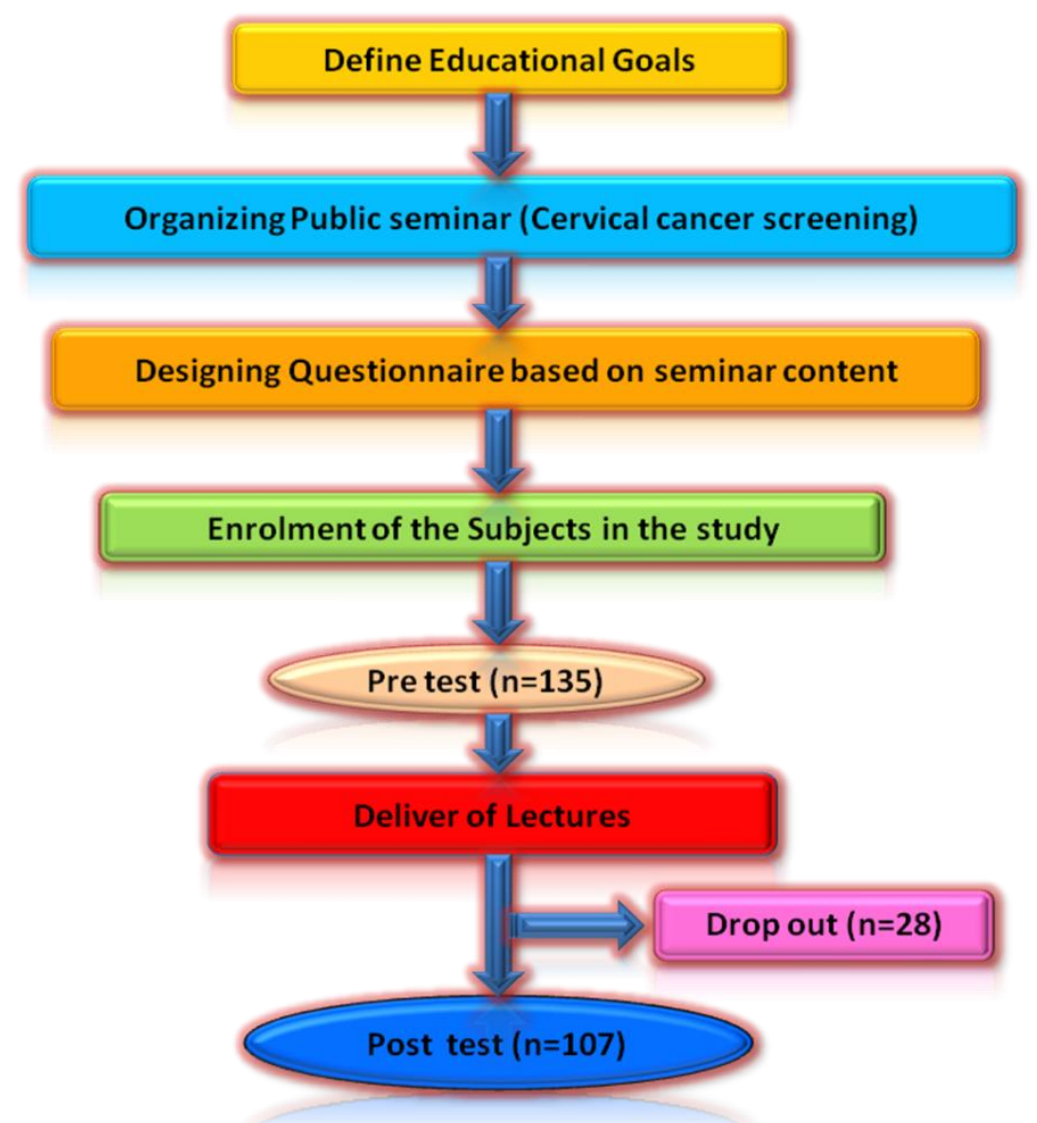

Figure 1. Flow chart of the Study

\section{Results}

Demographic and socio-economic information of study subjects are shown in Table 1 . The mean age of subjects was 39.4years $(\mathrm{SD}=10.3)$. Majority of respondents were married (85 percent) and also most of their educational level was community college (35.5 percent). Most of the respondents were covered by health insurance (66.4 percent).

Table 1: Socio-demographic profile of the respondents

\begin{tabular}{|c|c|c|c|}
\hline \multicolumn{2}{|c|}{ CHARACTERISTICS } & \multirow[t]{2}{*}{$\mathbf{N}$} & \multirow[t]{2}{*}{$\%$} \\
\hline $\begin{array}{l}\text { Total subjects } \\
\text { Mean age }\end{array}$ & $\begin{array}{c}107 \\
39.4 \pm 10.3\end{array}$ & & \\
\hline $\begin{array}{l}\text { Age group } \\
20-30\end{array}$ & & 36 & 33.6 \\
\hline $31-40$ & & 16 & 15 \\
\hline $41-50$ & & 34 & 31.8 \\
\hline $51-60$ & & 21 & 19.6 \\
\hline$>60$ & & 0 & 0 \\
\hline Marital status & & & \\
\hline
\end{tabular}




\begin{tabular}{|l|l|l|}
\hline Single & 14 & 13.1 \\
\hline Married & 91 & 85 \\
\hline Divorce & 0 & 0 \\
\hline Widow & 2 & 1.9 \\
\hline Educational level & & \\
\hline Primary school & 4 & 3.7 \\
\hline High school & 22 & 20.6 \\
\hline Community college & 38 & 35.5 \\
\hline B.Sc & 23 & 21.5 \\
\hline M.Sc & 15 & 14 \\
\hline Ph.D & 5 & 4.7 \\
\hline Health Insurance & & \\
\hline Yes & 71 & 66.4 \\
\hline No & 36 & 33.6 \\
\hline
\end{tabular}

The finding revealed that correct responses increased from 39\% (pre seminar) to $71 \%$ (post seminar) and there was a significant difference in means scores of knowledge in pretest and post-test $(\mathrm{P}<0.001)$ (Figure 2$)$.

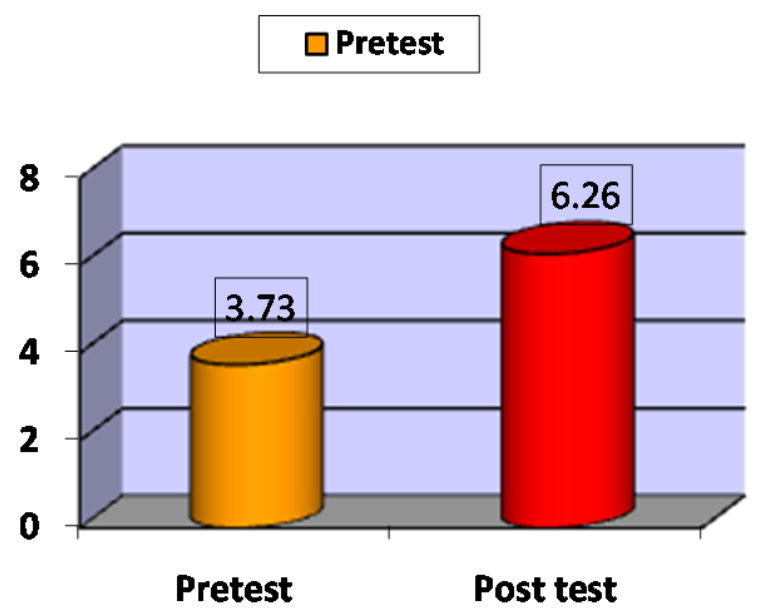

Figure 2. Mean score of respondent's knowledge by pre and post test

As the result show (Table 2), the number of the correct answers has increased during the post test. Chi-square test employed in order to test the efficacy of seminar to inseminate cervical cancer knowledge to the respondents and the finding indicated significant improvement of subjects' knowledge in all knowledge questions following the intervention $(\mathrm{P}<0.05)$.

Table 2. Chi-square Test of Correct Response of respondents in pre and post-test by questions 


\begin{tabular}{|c|c|c|c|c|c|}
\hline \multirow{3}{*}{ Questions } & \multicolumn{4}{|c|}{ Correct Response } & \multirow[t]{3}{*}{$\chi^{2}$} \\
\hline & \multicolumn{2}{|c|}{ Pre Test } & \multicolumn{2}{|c|}{ Post Test } & \\
\hline & No. & $\%$ & No. & $\%$ & \\
\hline Q1. Primary Purpose of Pap Smear & 36 & 33.64 & 65 & 60.74 & $16.78 *$ \\
\hline Q2. Suitable age for first Pap Test & 42 & 39.25 & 69 & 64.48 & $24.49 *$ \\
\hline Q3. Cervical Cancer Risk Factors & 53 & 49.53 & 71 & 66.35 & $14.23 *$ \\
\hline Q4. Awareness regarding Recommended Pap Test & 32 & 29.90 & 58 & 54.20 & $31.42 *$ \\
\hline Q5. Susceptibility of older women for Cervical cancer & 44 & 41.12 & 68 & 63.55 & $15.08 *$ \\
\hline Q6. Sexual activity as risk factor of Cervical cancer & 50 & 46.72 & 73 & 68.22 & $35.12 *$ \\
\hline Q7. Cervical cancer treatment & 47 & 43.92 & 70 & 65.42 & $25.32 *$ \\
\hline Q8. Diagnosis of Cervical cancer by Pap test & 45 & 42.05 & 76 & 71.02 & $23.02 *$ \\
\hline Q9. Cure for Cervical cancer & 36 & 33.64 & 65 & 60.74 & $22.24 *$ \\
\hline Q10. Importance of Pap Test & 49 & 45.79 & 77 & 71.96 & 33.05* \\
\hline
\end{tabular}

*. Indicated statistical significant at $\mathrm{p}<0.05$

The results of the present study revealed that the scientific seminar improved the respondents' attitude about cervical cancer screening significantly $(\mathrm{p}<0.05)$ particularly self administered pap test. This may signify that any improvement in a person's knowledge about something will ensue to a better attitude on it. The finding also illustrated a significant correlation between respondents' knowledge and their educational level and marital status $(\mathrm{p}<0.05)$.

\section{Discussion}

Despite the fact that the Pap smear program was introduced about four decades ago in Malaysia, no reduction in the prevalence of cervical cancer has been noted. Malaysian women have low rates of cervical cancer screening awareness, intention, and utilization (Nor Hayati, 2003), even among the highly educated (Lim, 2003).The result demonstrated the poor knowledge and attitude of respondents regarding cervical cancer screening which was in agreement with the study in the South-East Asia that showed low level of cervical cancer screening information (Al-Meer et al., 2011; Ma et al., 2012). Lack of knowledge about cervical cancer and pap smear program can be a major obstacle in pap smear uptake (Hyacinth et al., 2012; Singh and Badaya, 2012 ). The result underlined the necessity of disseminating factual information about the Pap smear test, its procedure, and the benefits of early detection of cervical cancer.

Knowledge of both cancer of the cervix and Pap smear improved significantly after the intervention and more respondents were knowledgeable about the disease and about Pap smear. Since the post-test was done immediately after the intervention, it could be assumed that the improvement in these variables was probably due to the health education intervention through scientific lectures during seminar that were delivered. These results were consistent with other scholars' finding (Adamu et al., 2012; Dim et al., 2009; Hou et al., 2004; Papa et al., 2009) who found the efficacy of such educational programs. Accordingly same effectiveness was proved not only for disseminating cancer screening information but also for other health messages such as health hazard of cigarette smoking (Salaudeen et al., 2011; Lee and Wang, 2002), health education for family planning (Mahamed et al., 2012) and so on.

The attitude of the respondents was also not favorable prior to the intervention. This may be related to their perception of the test. On the other hand almost of women in Malaysia reported 
high levels of embarrassment and anxiety about having vaginal or pelvic examination by male doctors. Due to religious affiliation and cultural beliefs, Muslim women in particular felt most comfortable with female health care providers. Many of them did not participate in screening due to perceived unavailability of female doctors. This is consistent with other research with Asian women, as many studies reported that they preferred female doctors to perform physical examination on intimate body parts and were highly embarrassed with male health providers (Nguyen et al., 2002; Holroyd et al., 2004). Scholars have shown that easy access to female doctors contributed to the increased likelihood of receiving a Pap smear test (Holroyd et al., 2004). Therefore, since current study has focused on a novel method of collecting samples for pap test by participants (KATO Device) which help women to overcome on their embarassement, so change of their attitude is probably due to this matter. The impact of social and cultural factors and religious norms regarding Pap smear screening is undeniable and in need of attention among Asian women (Holroyd et al., 2004; Islam et al., 2006). Cultural beliefs and religious affiliation shape health beliefs among these women and provoke confusion, hesitance, and barriers to screening.

\section{Conclusion}

An educational intervention had a positive effect on short-term knowledge and awareness of cervical cancer in Malaysian women. Additional research is necessary to assess long-term retention of information and what effect, if any, increased knowledge has on health behaviour. This study has demonstrated that women's negative attitudes and beliefs deterred them from regular cervical cancer screening. The findings suggested that lack of knowledge, information about Pap smear tests, and poor communication by health care providers had contributed to women's non-attendance at Pap smear screening. These findings have positive implications for cervical cancer screening education efforts and public health interventions. In summary, health education and considering cultural beliefs and religious affiliation would provide an opportunity to increase cervical screening uptake by Malaysian women.

\section{References}

Adamu AN, Abiola AO, Ibrahim M. The effect of health education on the knowledge, attitude, and uptake of free Pap smear among female teachers in Birnin-Kebbi, North-Western Nigeria. Niger J Clin Pract. 2012;15:326-32.

Al-Meer, F.M. , Aseel, M.T. , Al-Khalaf, J. , Al-Kuwari, M.G. , and Ismail, M.F.S. (2011). Knowledge, attitude and practices regarding cervical cancer and screening among women visiting primary health care in Qatar. Eastern Mediterranean Health Journal. 17(11);855-861.

Chee, H.L., Rashidah, S., Shamsuddin, K., and Intan, O. (2003). Factors related to the practise of breast self examination (BSE) and Pap smear screening among Malaysian women workers in selected electronics factories. BMC Women's Health. 3:3.

Dim CC, Ekwe E, Madubuko T, Dim NR, Ezegwui HU. Improved awareness of Pap smear may not affect its use in Nigeria: A case study of female medical practitioners in Enugu, southeastern Nigeria. Trans R Soc Trop Med Hyg. 2009;103:852-54.

Holroyd W, Twinn, Adab P (2004). Social-cultural influences on Chinese women's attendance for cervical screening. J Adv Nursing. 46, 42-52. 
Hou SI, Fernandez ME, Parcel GS. Development of a Cervical cancer Educational Program for Chinese Woman using Intervention Mapping. Health Promot Pract. 2004;5:80-7.

Hyacinth HI, Adekeye OA, Ibeh JN, Osoba T (2012) Cervical Cancer and Pap Smear Awareness and Utilization of Pap Smear Test among Federal Civil Servants in North Central Nigeria. PLOS ONE 7(10): e46583. doi:10.1371/journal.pone.0046583.

Institute for Public Health. 2008. The Third National Health and Morbidity Survey 2006: Women's Health. Ministry of Health Malaysia, Malaysia.

Islam, N., Kwon, S.C., Senie, R., and Kathuria, N. (2006). Breast and Cervical Cancer Screening Among South Asian Women in New York City. Journal of Immigrant and Minority Health . 8( 3); 211-221.

Kotaska, A.J. and Matisic, J.P. (2003). Cervical cleaning improves Pap smear quality. Canadian Medical Association Journal. 169(7):666-9.

Kuie, T.S. (1996). Cervical Cancer: Its Causes and Prevention. Singapore: Times Book International.

Lee FH, Wang HH.(2002). Effects of health education on prevention of smoking among eight-grade students. Kaohsing J Med Sci. 18(6): 295-304.

Leyva, M., Byrd, T., \& Tarwater, P. (2006). Attitudes towards cervical cancer screening: a study of beliefs among women in Mexico. Californian Journal of Health Promotion. 4(2), 13-24.

Lim, G. C. C. (2003). Cancer in Malaysia-There is a light at the end of the tunnel. Malaysia Medical Association. Retrieved July 28, 2007, from http://www.mma.org.my/mjm/2003.htm

Ma, G.X., Fang, C. Y., Feng, Z., Tan, Y., Gao,W., Ge, S., and Nguyen, C. (2012). Correlates of Cervical Cancer Screening among Vietnamese American Women. Infectious Diseases in Obstetrics and Gynecology.

Mahamed, F., Parhizkar, S. and Raygan Shirazi, A. (2012). Impact of Family Planning Health Education on the Knowledge and Attitude among Yasoujian Women. Global Journal of Health Science. 4( 2);110-118.

Markovic, M., Kesic, V., Topic, L., \& Matejic, B. (2005). Barriers to cervical cancer screening: a qualitative study with women in Serbia. Social Science \& Medicine. 61(12), 2528-2535.

Nguyen, T. T., McPhee, S. J., Nguyen, T., Lam, T., and Mock, J. (2002). "Predictors of cervical pap smear screening awareness, intention, and receipt among Vietnamese-American women," American Journal of Preventive Medicine. 23(3); 207-214.

Nor Hayati, O. (2003). Cancer of the cervix-From bleak past to bright future: A review, with an emphasis on cancer of the cervix in Malaysia. Malaysian Journal of Medical Sciences, 10, $13-26$.

Papa D, Moore Simas TA, Reynolds M, Melnitsky H. (2009). Assessing the role of education in women's knowledge and acceptance of adjunct high-risk human Papillomavirus testing for cervical cancer screening. J Low Genit Tract Dis. 13:66-71. 
Reyes-Ortiz, C. A., Camacho, M. E., Amador, L. F., Velez, L. F., Ottenbacher, K. J., \& Markides, K. S. (2007). The impact of education and literacy levels on cancer screening among older Latin American and Caribbean adults. Cancer Control. 14 (4), 388-395.

Salaudeen, A., Musa, O., Akande, A., Bolarinwa, O. (2011). Effects of health education on cigarette smoking habits of young adults in tertiary institutions in a northern Nigerian state, Health science journal. 5(3); 216-228.

Shamsuddin, K. and S. Zailiza. (2001). Factors associated with Pap Smear screening among women workers in Universiti Kebangsaan Malaysia. Medical Journal of Malaysia. 56(suppl B): 115 .

Singh S, Badaya S (2012) Factors Influencing uptake of Cervical Cancer Screening among Women in India: A Hospital based Pilot Study. J Community Med Health Educ. 2:157. doi:10.4172/2161-0711.1000157.

Wells, C. S. \& Wollack, J.A. (2003). An Instructor's Guide to Understanding Test Reliability. Testing \& Evaluation Services. University of Wisconsin.

Wong, L. P., Y. L. Wong, W. Y, Low, E. M. Khoo, and R. Shuib. (2009). Knowledge and awareness of cervical cancer and screening among Malaysian women who have never had a Pap smear: a qualitative study. Singapore Medical Journal. 50(1): 49-53. 